\title{
Feasibility of CT-based intraoperative 3D stereotactic image-guided navigation in the upper cervical spine of children 10 years of age or younger: initial experience
}

\author{
Timothy J. Kovanda, MD, ${ }^{1}$ Shaheryar F. Ansari, MD, ${ }^{1}$ Rabia Qaiser, MD, ${ }^{1}$ and \\ Daniel H. Fulkerson, MD2
}

\begin{abstract}
Department of ${ }^{1}$ Neurological Surgery and ${ }^{2}$ Division of Pediatric Neurosurgery, Goodman Campbell Brain and Spine, Indiana University School of Medicine, Indianapolis, Indiana
\end{abstract}

\begin{abstract}
OBJECT Rigid screw fixation may be technically difficult in the upper cervical spine of young children. Intraoperative stereotactic navigation may potentially assist a surgeon in precise placement of screws in anatomically challenging locations. Navigation may also assist in defining abnormal anatomy. The object of this study was to evaluate the authors' initial experience with the feasibility and accuracy of this technique, both for resection and for screw placement in the upper cervical spine in younger children.
\end{abstract}

METHODS Eight consecutive pediatric patients 10 years of age or younger underwent upper cervical spine surgery aided by image-guided navigation. The demographic, surgical, and clinical data were recorded. Screw position was evaluated with either an intraoperative or immediately postoperative CT scan.

RESULTS One patient underwent navigation purely for guidance of bony resection. A total of 14 navigated screws were placed in the other 7 patients, including $5 \mathrm{C}$-2 pedicle screws. All 14 screws were properly positioned, defined as the screw completely contained within the cortical bone in the expected trajectory. There were no immediate complications associated with navigation.

CONCLUSIONS Image-guided navigation is feasible within the pediatric cervical spine and may be a useful surgical tool for placing screws in a patient with small, often difficult bony anatomy. The authors describe their experience with their first 8 pediatric patients who underwent navigation in cervical spine surgery. The authors highlight differences in technique compared with similar navigation in adults.

http://thejns.org/doi/abs/10.3171/2015.2.PEDS14556

KEY WORDS spine; cervical; pediatric; stereotactic; navigation

$\mathrm{S}$ TEREOTACTIC CT-guided intraoperative navigation is becoming commonplace in adult spine surgery. Navigation may improve the accuracy of screw placement, guide resection, and allow confirmation of appropriate screw position before completion of the case. Previous studies have evaluated the efficacy of navigation in the adult cervical spine, ${ }^{16,17,28,36}$ but there is very little information regarding its use in children. There are a number of specific concerns and challenges in performing navigation in the cervical spine of young children. The authors review their initial experience with CT-guided navigation in 8 children 10 years of age or younger.

\section{Methods}

A retrospective review of the first 8 consecutive patients 
with upper cervical spine surgery using intraoperative cone-beam CT (O-arm, Medtronic) coupled with stereotactic navigation (StealthStation, Medtronic) at Riley Hospital for Children in Indianapolis, Indiana, was performed. The following data were recorded for each patient: age, diagnosis, results of preoperative neurological examination, procedure performed, instrumentation used, estimated blood loss, operative time, length of hospital stay, complications, and clinical course. The study began after Institutional Review Board approval was received.

Screw position was assessed by either an intraoperative or immediately postoperative CT scan, according to the modified classification of Gertzbein and Robbins. ${ }^{11,23,35}$ We considered "properly placed" screws to be Gertzbein and Robbins Grade A, i.e., the screw completely contained within the cortical bone, allowing for bicortical purchase when intended. Furthermore, a "properly placed" screw conformed to the expected trajectory and anatomical target indicated by the navigation device.

\section{Surgical Technique}

Prior to surgery, all images are reviewed. For posterior procedures, all patients are placed in the prone position with 3-point pin fixation. A standard suboccipital and upper cervical spine exposure is performed.

The navigation system requires a reference frame that may be attached to the head holder or directly to the spine. Our preference is to attach the frame directly to a spinous process for screw placement in posterior surgeries. The frame is attached to the head holder for ventral approaches (the patient in Case 8).

In younger patients, generally only the spinous processes of C-2 and C-7 are large enough to support the frame. In most cases, we attach the reference frame to the spinous process of C-2. Figure 1 shows the layout of the room, with the camera at the head of the bed and the reference frame leaning cephalad. This allows the proper angle for placement of a C-2 pedicle screw without interference from the frame. This orientation also allows placement of C-1 lateral mass screws.

After attaching the reference frame, the wound is filled with irrigation. Self-retaining retractors are left in place. The wound is covered with sterile towels, followed by sterile sheets, with the reference frame visible. The O-arm device is brought into the field and the relevant anatomy is centered with scout $\mathrm{x}$-ray views. A CT scan is performed via an O-arm "spin." The O-arm is set to preprogrammed settings for a "small" spine patient. The O-arm and drapes are removed, the instruments are registered to the navigation device, and the accuracy is confirmed with bony landmarks.

For screw placement, an entry point is chosen based on navigation (Fig. 2A). A projection is used to plan the trajectory of the screw. The trajectory is chosen to afford acceptable bony purchase without undue risk to the vertebral artery or nervous structures. A small hole in the bony cortex is created with a high-speed drill. A navigated hand drill is then used to cannulate the pedicle or pars. The width and length of the screw is projected on the navigation device (Fig. 2B). A ball probe is used to palpate the pedicle. The pedicle is then tapped with a navigated instrument and a screw is placed.

After placing the navigated screws, the entry point for the occipital screws is determined. Navigation allows precise location of the thickest area of the bony keel. This is important in small children because, only a few millimeters off the midline, the skull may be too thin to accommodate a screw in a young child. The occipital screw

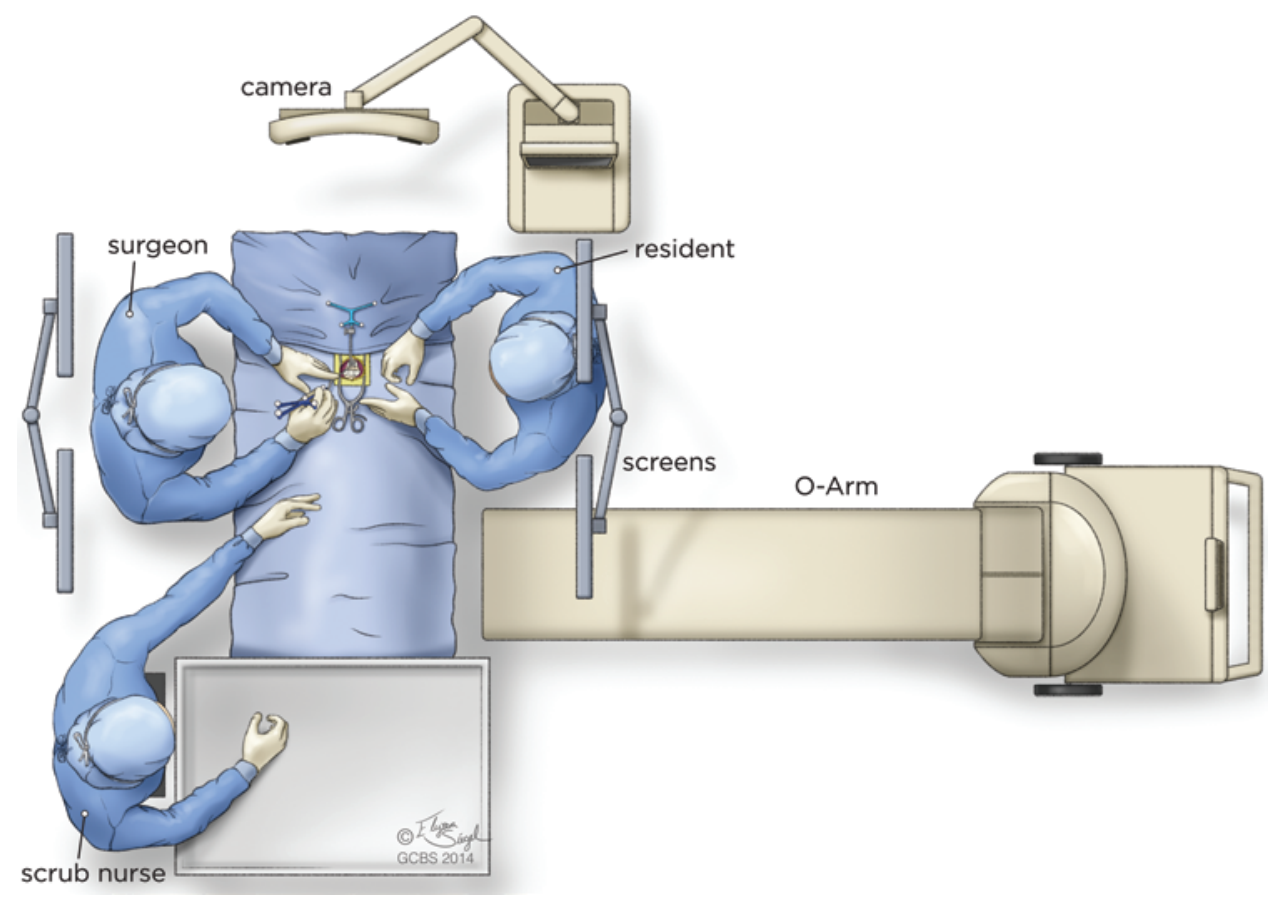

FIG. 1. Artist's depiction of the layout of the operating room for posterior procedures. Copyright Elyssa Siegel. Published with permission. 

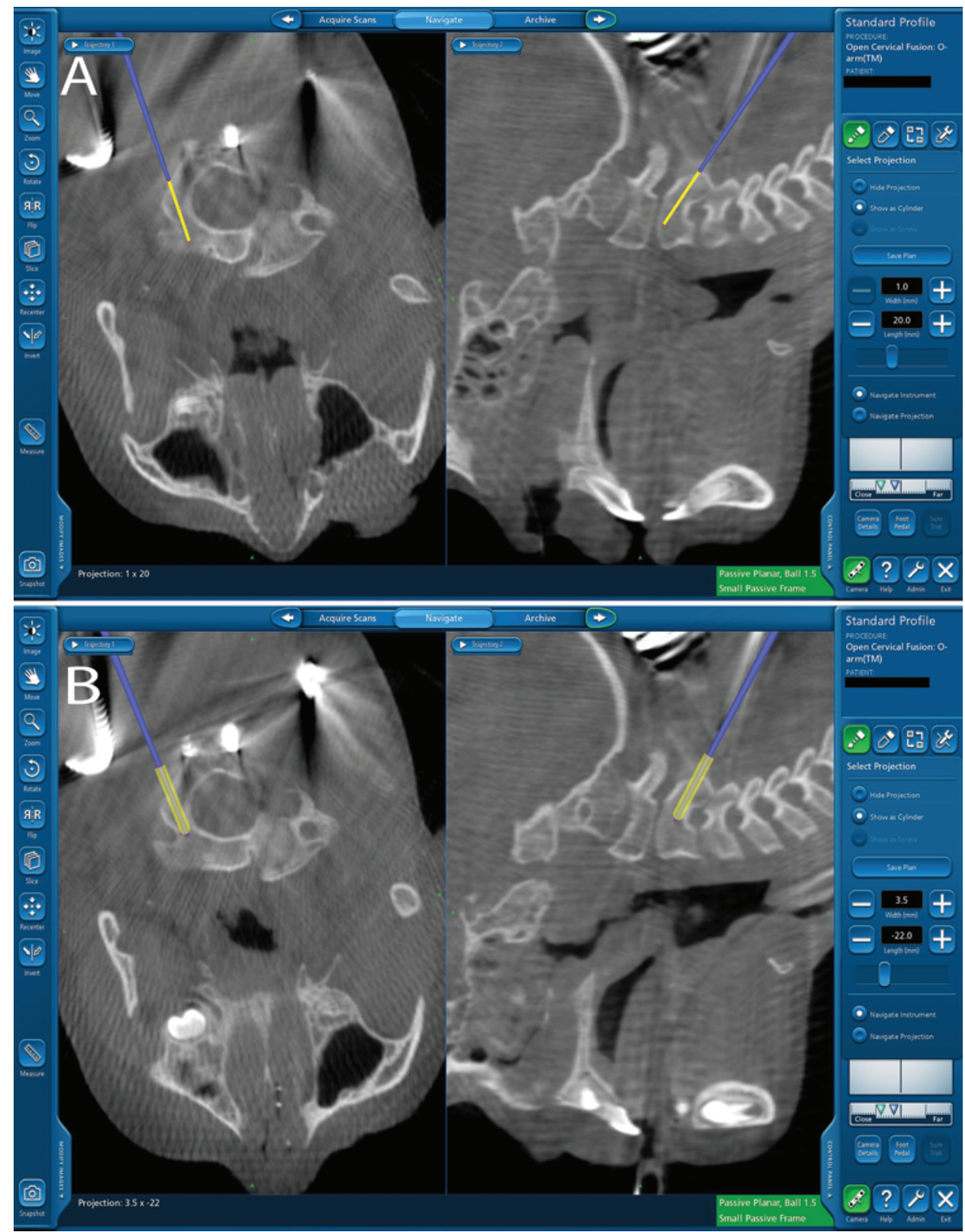

FIG. 2. The screw entry point to $\mathrm{C}-2$ is determined with the navigation system. A: After identifying the entry point, a thin projection is used to plan the screw trajectory. The navigation device allows visualization in multiple planes, including axial views. B: After the trajectory is determined, a virtual screw is built, allowing planning of the screw width and length. Figure is available in color online only.

trajectory is generally fixed as perpendicular to the outer bone cortex. Thus we use navigation only for entry point localization, not for occipital screw placement.

Once the navigation is completed, the reference frame is removed. Non-navigated screws are then placed. C-2 translaminar screws are placed according to the modified Wright's technique using anatomical landmarks. ${ }^{18}$ Prior to closure, the O-arm is brought back into the field and a second "spin" is performed. This allows confirmation of hardware placement prior to closure. We reattach the reference frame in case screw replacement or repositioning is needed.

\section{Results}

A total of 8 consecutive patients were studied (Table 1). There were 4 girls and 4 boys, ranging from 17 months to 10 years of age. Seven patients had instrumentation placed with navigation. Navigation was used to guide resection in 3 patients (patients in Cases 5, 7, and 8). The patient in Case 8 had posterior instrumentation placed at a prior surgery; navigation was used to assist the ventral bony decompression.

A total of 14 screws were placed with navigation (Table 2). There were 5 screws placed in the pedicle of $\mathrm{C}-2$. The 
TABLE 1. Demographic and clinical data for the study group

\begin{tabular}{|c|c|c|c|c|c|c|c|c|}
\hline $\begin{array}{c}\text { Case } \\
\text { No. }\end{array}$ & Age & Sex & Indication for Surgery & Procedure & $\mathrm{EBL}(\mathrm{ml})$ & $\begin{array}{l}\text { Surgical Time } \\
\text { (hrs:mins) }\end{array}$ & $\begin{array}{l}\text { Hospital } \\
\text { Stay } \\
\text { (days) }\end{array}$ & Notes \\
\hline 1 & $17 \mathrm{mos}$ & $\mathrm{F}$ & Trauma & Oc-C3 fusion & 50 & $3: 35$ & 12 & $\begin{array}{l}\text { Concurrent head injury, significant } \\
\text { ligamentous disruption, \& } \\
\text { traumatic dural tear }\end{array}$ \\
\hline 2 & 6 yrs & M & Trauma & Oc-C3 fusion & 100 & $3: 02$ & 6 & $\begin{array}{l}\text { Concurrent head injury \& facial } \\
\text { fractures requiring surgery, sig- } \\
\text { nificant ligamentous disruption }\end{array}$ \\
\hline 3 & 4 yrs & M & $\begin{array}{l}\text { Congenital spinal } \\
\text { anomalies }\end{array}$ & C1-2 fusion & 50 & $2: 40$ & 3 & $\begin{array}{l}\text { Klippel-Feil, multiple fusion } \\
\text { abnormalities, gross C1-2 } \\
\text { instability }\end{array}$ \\
\hline 4 & 3 yrs & $M$ & $\begin{array}{l}\text { Congenital spinal } \\
\text { anomalies }\end{array}$ & Oc-C2 fusion & 20 & $3: 17$ & 4 & $\begin{array}{l}\text { Multiple congenital bony anoma- } \\
\text { lies including complete agen- } \\
\text { esis of the odontoid process }\end{array}$ \\
\hline 5 & 9 yrs & $M$ & C-1 osteoblastoma & Oc-C2 fusion & 350 & 4:09 & 4 & $\begin{array}{l}\text { Expansile, hemorrhagic bony } \\
\text { tumor measured } 2.5 \times 3.2 \times \\
1.9 \mathrm{~cm}\end{array}$ \\
\hline 6 & 4 yrs & $\mathrm{F}$ & $\begin{array}{l}\text { Congenital instability, } \\
\text { Shprintzen-Gold- } \\
\text { berg syndrome }\end{array}$ & Oc-C4 fusion & 50 & $3: 52$ & 3 & $\begin{array}{l}\text { Shprintzen-Goldberg syndrome } \\
\text { w/ congenital stenosis \& } \\
\text { myelomalacia at the foramen } \\
\text { magnum, pronounced occipito- } \\
\text { cervical instability }\end{array}$ \\
\hline 7 & $10 \mathrm{yrs}$ & $\mathrm{F}$ & $\begin{array}{l}\text { C-3 aneurysmal bone } \\
\text { cyst }\end{array}$ & $\begin{array}{l}\text { C-3 corpectomy, com- } \\
\text { bined AP C2-4 } \\
\text { fusion }\end{array}$ & 750 & $7: 35$ & 2 & $\begin{array}{l}\text { AP procedure w/ C-3 corpectomy } \\
\& \text { resection of aneurysmal } \\
\text { bone cyst }\end{array}$ \\
\hline 8 & 3 yrs & $\mathrm{F}$ & $\begin{array}{l}\text { Congenital upper cervi- } \\
\text { cal spine kyphosis } \\
\text { w/ prior laminectomy } \\
\text { \& posterior fusion }\end{array}$ & $\begin{array}{l}\text { Transoral anterior cor- } \\
\text { pectomy of C1-4 } \\
\text { (Stage 1); revision } \\
\text { of posterior fusion } \\
\text { (Stage 2) }\end{array}$ & $\begin{array}{r}100 \text { (Stage 1); } \\
50 \text { (Stage 2) }\end{array}$ & $\begin{array}{l}\text { 9:47 (Stage 1); } \\
\text { 2:55 (Stage } \\
\text { 2) }\end{array}$ & 9 & $\begin{array}{l}\text { Congenital kyphosis w/ multiple } \\
\text { prior laminectomies \& posterior } \\
\text { fusion. Two-stage procedure. } \\
\text { Ventral decompression on Day } \\
1 \text { w/ exploration \& augmenta- } \\
\text { tion of posterior fusion on } \\
\text { Day } 2 \text {. }\end{array}$ \\
\hline
\end{tabular}

EBL = estimated blood loss.

measurement of the pedicle width is given. In 1 case, the height of the pedicle measured on sagittal CT scan was the smallest dimension; this measurement is recorded. The pedicle widths ranged from 3.6 to $5.7 \mathrm{~mm}$ (average $4.2 \pm 0.9 \mathrm{~mm})$.

All 14 screws were "properly placed" (Gertzbein and Robbins Grade A), as confirmed by CT scan. There were no complications with screw placement, including both screws placed with navigation and those placed with a freehand technique. No patient had a decline in neurological status after the surgery. There were no injuries to vertebral or carotid arteries. No patients required revision surgery in the immediate postoperative period.

\section{Illustrative Cases Case 1}

A 17-month-old child was involved in a high-speed motor vehicle accident. Initial CT scanning showed a cranial subdural hematoma and anterior soft-tissue swelling in the upper cervical spine. MRI showed significant ligamentous damage and anterior soft-tissue swelling (Fig. 3A). The subdural hematoma did not require surgical intervention. The cervical injury was considered mechanically unstable. Despite her injuries, she was neurologically intact. After the patient became clinically stabilized, she was taken to the operating room for occipitocervical fusion.

We planned fixation at $\mathrm{C}-2$, with a combination of a translaminar screw and a contralateral pedicle screw. Given her young age, her pedicle was narrow (Fig. 3B). With navigation, a $3.5-\mathrm{mm}$ screw was placed safely in a pedicle measuring $3.6 \mathrm{~mm}$ in width (Fig. 3C). The patient recovered well from surgery and has no neurological deficits.

\section{Case 7}

A 10-year-old girl presented with sudden onset of atraumatic neck pain. Imaging showed a pathologic fracture of C-3 (Fig. 4A). A CT angiogram showed a lesion that extended from the vertebral body to the facet and completely surrounded the right vertebral artery (Fig. 4B). She had no neurological deficits.

The patient was taken for a combined anterior-pos- 
TABLE 2. Navigation data for upper cervical spine surgery in 8 pediatric patients

\begin{tabular}{|c|c|c|c|c|c|c|}
\hline $\begin{array}{l}\text { Case } \\
\text { No. }\end{array}$ & Procedure & $\begin{array}{l}\text { Navigation for } \\
\text { Resection }\end{array}$ & $\begin{array}{c}\text { Navigation for } \\
\text { Screw Placement }\end{array}$ & Navigated Screws & $\begin{array}{l}\text { C-2 Pedicle } \\
\text { Width }(\mathrm{mm})\end{array}$ & $\begin{array}{c}\text { Properly } \\
\text { Placed Screw }\end{array}$ \\
\hline 1 & Oc-C3 fusion & & $\bullet$ & 1: C-2 pedicle screw & 3.60 & 1 \\
\hline 2 & Oc-C3 fusion & & $\bullet$ & 1: C-2 pars screw & NA & 1 \\
\hline 3 & C1-2 fusion & & $\bullet$ & $\begin{array}{l}\text { 4: C-2 pedicle screw (1); C-1 } \\
\text { lat mass screw (2); C-2 } \\
\text { translaminar screw (1) }\end{array}$ & 4.16 & 4 \\
\hline 4 & Oc-C2 fusion & & $\bullet$ & 1: C-2 pedicle screw & 3.62 & 1 \\
\hline 5 & Oc-C2 fusion & $\bullet$ & $\bullet$ & 1: C-2 pedicle screw & 5.72 & 1 \\
\hline 6 & Oc-c4 fusion & & $\bullet$ & 1: C-2 pedicle screw & 3.90 & 1 \\
\hline 7 & C-3 corpectomy, combined AP C2-4 fusion & $\bullet$ & $\bullet$ & $\begin{array}{l}\text { 5: C-2 pars screws (2); C-3 (1) } \\
\text { \& C-4 (2) lat mass screws }\end{array}$ & NA & 5 \\
\hline 8 & $\begin{array}{l}\text { Ventral corpectomy of C1-4 (Stage 1), w/ } \\
\text { augmentation of posterior fusion (Stage 2) }\end{array}$ & $\stackrel{\bullet}{\bullet}$ & & 0 & NA & NA \\
\hline
\end{tabular}

$\mathrm{NA}=$ not applicable.

terior (AP) approach. A C-3 corpectomy was performed through an anterior approach. The anterior column was reconstructed with a biomechanical graft and cervical plate. The patient was flipped to the prone position for resection of the facet and posterior elements. Navigation was used to tailor the resection of the pedicle and to help identify the vertebral artery. Navigation was then used for placement of $2 \mathrm{C}-2$ pars screws (Fig. 4C) and lateral mass screws on the left C-3 and bilateral C-4 facets. An intraoperative view (Fig. 4D) shows the extent of resection with exposure of the thecal sac and vertebral artery. The final construct is shown in Fig. 4E.

\section{Discussion}

CT-based stereotactic navigation has gained acceptance in adult spine surgery. Potential advantages of navigation include improved accuracy with a decreased likelihood of reoperation or injury to vital neurovascular structures. ${ }^{31,37}$ Navigation also may aid in determining the extent of bony decompression. ${ }^{13}$

Previously, pediatric upper cervical fusion was achieved with nonrigid fixation and onlay techniques with postoperative halo fixation. ${ }^{27,32}$ Rigid screw fixation provides superior mechanical stability and improved fusion rates compared with nonrigid techniques., ${ }^{4,910,14,21}$ Rigid screw fixation often obviates the need for postoperative halo fixation. There are anatomical studies evaluating the feasibility of commercially available screws in the pediatric population. ${ }^{9,10}$

There are significant anatomical differences between pediatric and adult cervical spines. These differences include ligamentous laxity, increased mobility, incomplete ossification, potential congenital anomalies, and relatively small bone size.,12 Screw fixation in younger children may be technically difficult for these reasons. Improperly placed screws may injure vital structures or may have less mechanical stability compared with properly placed screws. We hoped that CT-guided navigation would allow precise placement of the largest possible screw in this small and possibly anomalous bone. The object of this study was to evaluate our initial experience with the feasibility of this technique in younger children.

We considered the C-2 screws to be the most critical
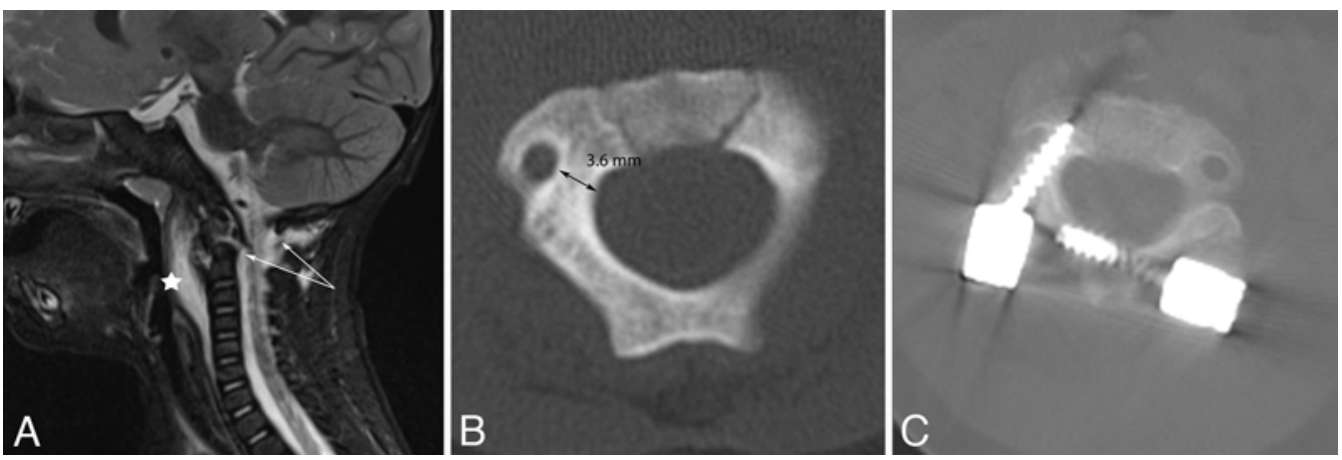

FIG. 3. Images of a 17-month-old child involved in a motor vehicle accident. A: A sagittal T2-weighted MRI image demonstrates extensive ligamentous injury (arrows) and ventral hematoma (star). The injury was considered mechanically unstable. B: Preoperative CT scan shows the C-2 pedicle width to be $3.6 \mathrm{~mm}$. A $3.5-\mathrm{mm}$ screw is placed in the pedicle with navigation. C: The postplacement image shows correct screw placement in the pedicle between the vertebral artery and the spinal canal. A contralateral translaminar screw is also shown. 


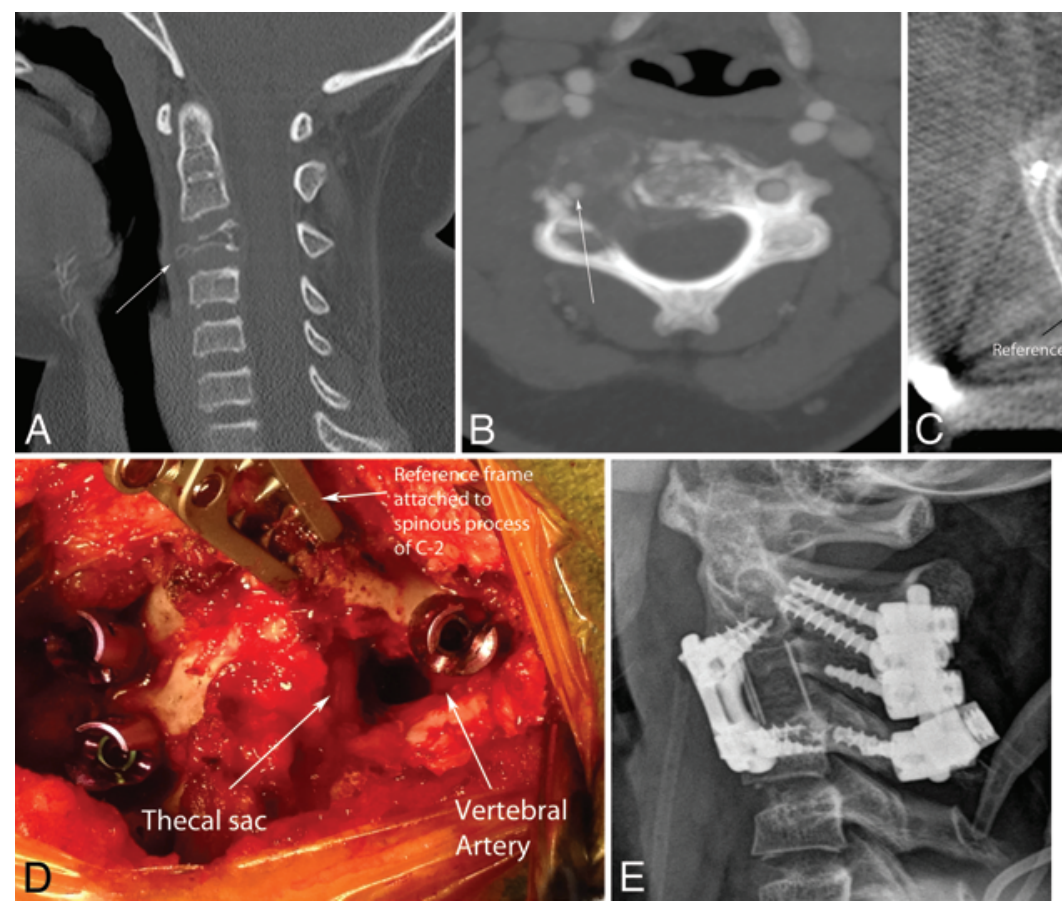

FIG. 4. A 10-year-old child presented with sudden, severe, atraumatic neck pain. A: Sagittal CT reconstruction demonstrates a pathologic fracture of C-3 (arrow). B: An axial view of a CT angiogram shows a destructive lesion encasing the right vertebral artery (arrow). C: Navigation was used to guide resection and to place the posterior instrumentation, including bilateral C-2 pars screws. D: An intraoperative photograph shows complete bony resection of the lesion, including skeletalization of the vertebral artery. E: The final instrumentation construct is shown on lateral $\mathrm{x}$-ray.

screws for navigation. Upper cervical constructs often rely on strong fixation in $\mathrm{C}-2$ because, even in younger children, this bone tends to be large enough to anchor stable screws. We have previously published the results and discussed the advantages of C-2 translaminar screws, namely, low risk of injury to the vertebral artery and large screw purchase area. ${ }^{30} \mathrm{~A}$ single C-2 translaminar screw can be placed in almost all young children. However, placement of 2 translaminar screws is generally not feasible in children younger than 16 years of age. ${ }^{4}$ Therefore, we prefer a construct with a translaminar screw coupled with either a contralateral C-2 pars or pedicle screw. An additional advantage of this construct is that only 1 vertebral artery is at risk from screw placement.

The choice of a pars or pedicle screw is dictated by the patient's bony anatomy and vertebral artery course. The C-2 pars lies between the inferior and superior articular facet, whereas the pedicle connects the inferior articular facet to the vertebral body. ${ }^{8,34}$ Both the pars and pedicle are potential targets for instrumentation. The pullout strength of a C-2 pedicle screw is greater than that of the pars..$^{34} \mathrm{In}$ very young children, the pars may be quite small and only allow a few threads of screw purchase; therefore, a pedicle screw may be preferred if anatomically feasible. This may require threading the screw through a very narrow area. The average width of the $\mathrm{C}-2$ pedicle isthmus of adults is approximately $6.9 \mathrm{~mm}$ in men and $6.5 \mathrm{~mm}$ in women. ${ }^{20} \mathrm{In}$ contrast, the pedicle widths of our 5 patients ranged from 3.6 to $5.7 \mathrm{~mm}$, with an average of $4.2 \pm 0.9 \mathrm{~mm}$. Navigation allows placement of a commercially available $3.5-\mathrm{mm}$ screw through this narrow target.
In the oldest patient (Case 7), we navigated subaxial lateral mass screws. Pedicle screws may have stronger pullout strength in the subaxial cervical spine, ${ }^{19}$ but have an increased risk of vertebral artery or nervous injury. Lateral mass screws are well accepted in adults, in whom fairly robust screws can be anchored safely. This patient's anatomy was closer to an adult configuration; thus we considered the lateral masses suitable for adequate screws.

There are previously published studies evaluating the efficacy of image-guided screw placement within the thoracolumbar spine of a pediatric population. Larson et al. studied the efficacy of image-guided navigation for the placement of pedicle screws in patients with pediatric scoliosis. ${ }^{24,25}$ The authors reported $96.4 \%$ accuracy while placing 984 pedicle screws in the thoracic, sacral, and lumbar spines of 50 consecutive patients. ${ }^{25}$ During this study period, the same navigation system was used to place 1511 adult pedicle screws with an accuracy of $98.2 \%{ }^{25}$ The accuracy within the pediatric population was favorable compared with the results of a meta-analysis assessing accuracy of non-navigated screws. ${ }^{25,26}$ Although this study has a number of limitations, it demonstrates a potential benefit for the use of navigation in the thoracolumbar spine.

One potential advantage of this technique is the ability to analyze screw placement before leaving the operating theater. Prior studies evaluated the use of intraoperative CT scanning for evaluation of hardware placement in pediatric cervical spine surgery. ${ }^{1,67,21}$ In an analysis of 31 pediatric patients with craniocervical instability, Karandikar et al. found intraoperative $\mathrm{CT}$ to be beneficial in reducing the number of revision surgeries for correction of misplaced 
instrumentation. ${ }^{21}$ In this study, 18 of $47 \mathrm{C} 1-2$ transarticular screws were "suboptimally placed" using standard techniques. Eleven of these 18 screws were revised during the same operation based on intraoperative CT results. Note that CT-guided navigation was not used to place the screws. Dahdaleh et al. used intraoperative CT to evaluate for appropriate reduction of basilar invagination and atlantoaxial rotary subluxation. ${ }^{6,7}$ Attia et al. used intraoperative $\mathrm{CT}$ to perform reduction and fusion in patients with traumatic atlantoaxial rotary subluxation. ${ }^{1}$ In their report, intraoperative $\mathrm{CT}$ was specifically used to guide $\mathrm{C}-1$ lateral mass and C-2 pedicle screws. ${ }^{1}$ Their evaluation was limited to a single pathology and procedure. Rajasekaran et al. describe the use of the Iso-C navigation system for placement of 51 cervical pedicle screws in 16 children. ${ }^{29}$

\section{Technical Nuances in Younger Children}

Screw navigation is now commonplace in adult spine surgery. There are a number of factors that must be considered when applying navigation techniques in young children. The physical size of the surgical exposure is much smaller in children compared with adults. The incision length required to expose the occiput to C-7 may be only a few centimeters in a very young child. The spinous processes are smaller. The restricted size limits the available space for surgical instruments. Therefore, placement of the reference frame must be very precise. The frame must be placed in such a way that it does not interfere with placing the screws. Therefore, we prefer to angle the frame superiorly, allowing access to C-1 and C-2.

The upper cervical spine is much more mobile in younger children compared with adults. Navigation relies on the relationship of the target to the reference frame. If the frame is fixed to the head holder, movement of the targeted bone will introduce error. Therefore, we attach the frame directly to the bone. Ideally, it should be attached to the bone where navigation is needed the most; this is generally C-2. Cannulating the pedicle requires application of downward force. This may move the bone in the flexible pediatric spine. If the frame is attached to the same bone, it will then move with the bone, keeping a consistent spatial relationship and thus preserving navigation accuracy (Fig. 5).

The reference frame must be placed with great care. The bone of the young child is much more fragile than that of an adult. The frame may crush or fracture the bone, even at C-2. The surgeon must take great care to ensure stable frame anchoring without damaging the underlying bone. After registration, accuracy must be confirmed with direct visual cues.

CT-guided navigation provides a number of advantages compared with standard fluoroscopic (C-arm) imaging. Fluoroscopic navigation allows visualization in lateral and $\mathrm{AP}$ orientations. In contrast, CT-guided imaging provides axial and trajectory views (Fig. 2A and B), in addition to lateral and AP views. This is critical when trying to navigate a small screw through a restricted area. Navigation allows planning of the entry point on the respective bony landmark and confirmation of the thickest part of the midline keel for occipital screws.

We did not encounter any complications with this tech-

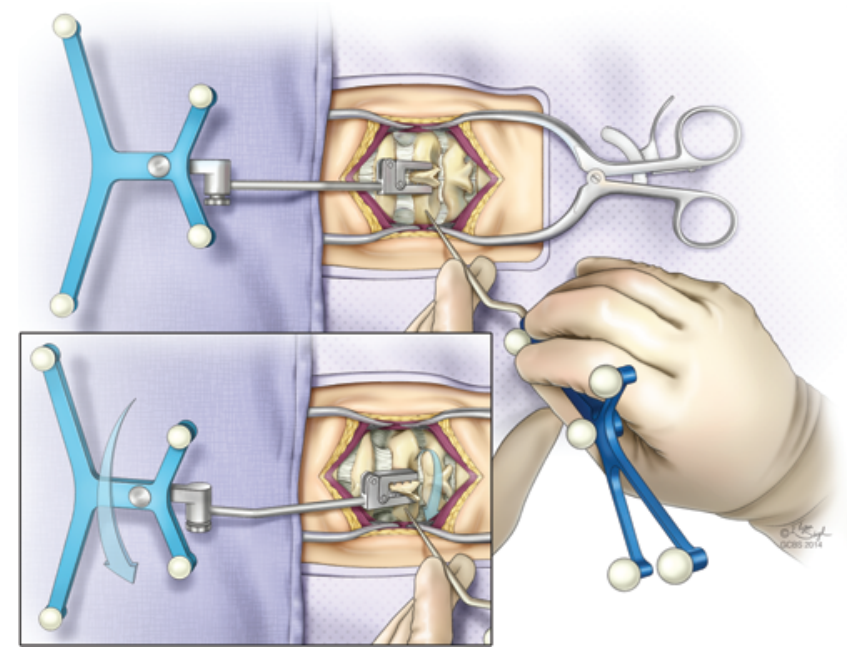

FIG. 5. Artist's depiction of the orientation of the reference frame. The frame is attached to the spinous process of C-2 and angled cephalad over the head. This allows the surgeon to work in the necessary space for C-2 (and C-1) screw placement, without interference from the frame. The pediatric cervical spine is much more mobile compared with an adult cervical spine. The $\mathrm{C}-2$ bone may move with minimal downward force, especially if the child has ligamentous injury. The frame will move with the bone, maintaining a consistent spatial orientation and preserving navigation accuracy (inset). Copyright Elyssa Siegel. Published with permission.

nique. We navigated 14 screws, including 5 into the C-2 pedicle. All screws were properly placed (Gertzbein and Robbins Grade A), as confirmed by CT scan.

\section{Potential Limitations}

Navigation is becoming commonplace in busy spine centers. However, there is a significant cost to purchasing an intraoperative CT scanner, navigation software, and the appropriate equipment. ${ }^{15}$ There may be a learning curve when applying new technology. Although we did not specifically compare the study population to our prenavigation cases, our anecdotal experience is that this technique decreases operative time once the staff is familiar with the surgical flow. This may be an area of future study.

Perhaps the most concerning aspect is the use of ionizing radiation, especially in a young child. Ionizing radiation is a risk factor for development of cancer. There are multiple mathematical models and population-based studies predicting an alarming number of future cancers directly caused by CT scanning. ${ }^{2,3,5,22,33}$ The use of intraoperative CT scanning exposes the patient to radiation, as does fluoroscopy. According to the manufacturer, a single spin in a small patient with current protocols provides a radiation dose of 19.68 mGy ("O-arm Imaging System Version 3.1 Dosimetry Report November 2009 with addendum August 2011," Medtronic Navigation, Inc., Document Nr: BI-150-00155 Rev 2). This is equivalent to 163 seconds of regular fluoroscope and 62 seconds of boost fluoroscopy. For multiple navigated screws (such as for scoliosis, long-segment fusions), we have found a decrease in total radiation exposure with a single spin, compared with multiple AP and lateral $\mathrm{C}$-arm views for each screw. We consider the radiation exposure to the surgical team 
to be an underappreciated and understudied factor. This technique significantly reduces the exposure to the surgeon and operating room staff, as only 1 or 2 doses of radiation are applied while the team is well away from the source. This is in contrast to potentially multiple exposures in close proximity to a fluoroscope.

\section{Conclusions}

The use of intraoperative image-guided navigation has the potential to improve accuracy of decompression and instrumentation while decreasing the morbidity and mortality associated with pediatric cervical spine operations. Our initial experience suggests that image-guided navigation may be a useful, efficacious tool for pediatric spine surgeons. In our initial experience, all 14 screws were properly placed, as confirmed by CT scan.

\section{References}

1. Attia W, Orief T, Almusrea K, Alfawareh M, Soualmi L, Orz $\mathrm{Y}$ : Role of the O-arm and computer-assisted navigation of safe screw fixation in children with traumatic rotatory atlantoaxial subluxation. Asian Spine J 6:266-273, 2012

2. Berrington de González A, Mahesh M, Kim KP, Bhargavan M, Lewis R, Mettler F, et al: Projected cancer risks from computed tomographic scans performed in the United States in 2007. Arch Intern Med 169:2071-2077, 2009

3. Brenner D, Elliston C, Hall E, Berdon W: Estimated risks of radiation-induced fatal cancer from pediatric CT. AJR Am J Roentgenol 176:289-296, 2001

4. Chern JJ, Chamoun RB, Whitehead WE, Curry DJ, Luerssen TG, Jea A: Computed tomography morphometric analysis for axial and subaxial translaminar screw placement in the pediatric cervical spine. J Neurosurg Pediatr 3:121-128, 2009

5. Chodick G, Ronckers CM, Shalev V, Ron E: Excess lifetime cancer mortality risk attributable to radiation exposure from computed tomography examinations in children. Isr Med Assoc J 9:584-587, 2007

6. Dahdaleh NS, Dlouhy BJ, Menezes AH: Application of neuromuscular blockade and intraoperative $3 \mathrm{D}$ imaging in the reduction of basilar invagination. J Neurosurg Pediatr 9:119-124, 2012

7. Dahdaleh NS, Dlouhy BJ, Menezes AH: One-step fixation of atlantoaxial rotatory subluxation: technical note and report of three cases. World Neurosurg 80:e391-e395, 2013

8. Ebraheim NA, Fow J, Xu R, Yeasting RA: The location of the pedicle and pars interarticularis in the axis. Spine (Phila Pa 1976) 26:E34-E37, 2001

9. Ferri-de-Barros F, Little DG, Bridge C, Cummine J, Cree AK: Atlantoaxial and craniocervical arthrodesis in children: a tomographic study comparing suitability of $\mathrm{C} 2$ pedicles and C2 laminae for screw fixation. Spine (Phila Pa 1976) 35:291-293, 2010

10. Geck MJ, Truumees E, Hawthorne D, Singh D, Stokes JK, Flynn A: Feasibility of rigid upper cervical instrumentation in children: tomographic analysis of children aged 2-6. J Spinal Disord Tech 27:E110-E117, 2014

11. Gertzbein SD, Robbins SE: Accuracy of pedicular screw placement in vivo. Spine (Phila Pa 1976) 15:11-14, 1990

12. Givens TG, Polley KA, Smith GF, Hardin WD Jr: Pediatric cervical spine injury: a three-year experience. J Trauma 41:310-314, 1996

13. Guppy KH, Chakrabarti I, Banerjee A: The use of intraoperative navigation for complex upper cervical spine surgery. Neurosurg Focus 36(3):E5, 2014

14. Haque A, Price AV, Sklar FH, Swift DM, Weprin BE, Sacco
DJ: Screw fixation of the upper cervical spine in the pediatric population. Clinical article. J Neurosurg Pediatr 3:529-533, 2009

15. Hodges SD, Eck JC, Newton D: Analysis of CT-based navigation system for pedicle screw placement. Orthopedics 35:e1221-e1224, 2012

16. Hott JS, Papadopoulos SM, Theodore N, Dickman CA, Sonntag VK: Intraoperative Iso-C C-arm navigation in cervical spinal surgery: review of the first 52 cases. Spine (Phila Pa 1976) 29:2856-2860, 2004

17. Ishikawa Y, Kanemura T, Yoshida G, Matsumoto A, Ito Z, Tauchi R, et al: Intraoperative, full-rotation, three-dimensional image (O-arm)-based navigation system for cervical pedicle screw insertion. J Neurosurg Spine 15:472-478, 2011

18. Jea A, Sheth RN, Vanni S, Green BA, Levi AD: Modification of Wright's technique for placement of bilateral crossing C2 translaminar screws: technical note. Spine J 8:656-660, 2008

19. Jones EL, Heller JG, Silcox DH, Hutton WC: Cervical pedicle screws versus lateral mass screws. Anatomic feasibility and biomechanical comparison. Spine (Phila Pa 1976) 22:977-982, 1997

20. Karaikovic EE, Daubs MD, Madsen RW, Gaines RW Jr: Morphologic characteristics of human cervical pedicles. Spine (Phila Pa 1976) 22:493-500, 1997

21. Karandikar M, Mirza SK, Song K, Yang T, Krengel WF III, Spratt KF, et al: Complex pediatric cervical spine surgery using smaller nonspinal screws and plates and intraoperative computed tomography. J Neurosurg Pediatr 9:594-601, 2012

22. Kleinerman RA: Cancer risks following diagnostic and therapeutic radiation exposure in children. Pediatr Radiol 36 (Suppl 2):121-125, 2006

23. Kosmopoulos V, Schizas C: Pedicle screw placement accuracy: a meta-analysis. Spine (Phila Pa 1976) 32:E111-E120, 2007

24. Larson AN, Polly DW Jr, Guidera KJ, Mielke CH, Santos ER, Ledonio CG, et al: The accuracy of navigation and 3D image-guided placement for the placement of pedicle screws in congenital spine deformity. J Pediatr Orthop 32:e23-e29, 2012

25. Larson AN, Santos ER, Polly DW Jr, Ledonio CG, Sembrano JN, Mielke CH, et al: Pediatric pedicle screw placement using intraoperative computed tomography and 3-dimensional image-guided navigation. Spine (Phila Pa 1976) 37:E188E194, 2012

26. Ledonio CG, Polly DW Jr, Vitale MG, Wang Q, Richards BS: Pediatric pedicle screws: comparative effectiveness and safety: a systematic literature review from the Scoliosis Research Society and the Pediatric Orthopaedic Society of North America task force. J Bone Joint Surg Am 93:1227-1234, 2011

27. Lowry DW, Pollack IF, Clyde B, Albright AL, Adelson PD: Upper cervical spine fusion in the pediatric population. $\mathbf{J}$ Neurosurg 87:671-676, 1997

28. Nottmeier EW, Young PM: Image-guided placement of occipitocervical instrumentation using a reference arc attached to the headholder. Neurosurgery 66 (3 Suppl Operative): $138-142,2010$

29. Rajasekaran S, Kanna PR, Shetty AP: Safety of cervical pedicle screw insertion in children: a clinicoradiological evaluation of computer-assisted insertion of 51 cervical pedicle screws including 28 subaxial pedicle screws in 16 children. Spine (Phila Pa 1976) 37:E216-E223, 2012

30. Savage JG, Fulkerson DH, Sen AN, Thomas JG, Jea A: Fixation with C-2 laminar screws in occipitocervical or C1-2 constructs in children 5 years of age or younger: a series of 18 patients. J Neurosurg Pediatr 14:87-93, 2014 
31. Schouten R, Lee R, Boyd M, Paquette S, Dvorak M, Kwon $\mathrm{BK}$, et al: Intra-operative cone-beam CT (O-arm) and stereotactic navigation in acute spinal trauma surgery. J Clin Neurosci 19:1137-1143, 2012

32. Smith MD, Phillips WA, Hensinger RN: Fusion of the upper cervical spine in children and adolescents. An analysis of 17 patients. Spine (Phila Pa 1976) 16:695-701, 1991

33. Stein SC, Hurst RW, Sonnad SS: Meta-analysis of cranial CT scans in children. A mathematical model to predict radiationinduced tumors. Pediatr Neurosurg 44:448-457, 2008

34. Su BW, Shimer AL, Chinthakunta S, Salloum K, Ames CP, Vaccaro AR, et al: Comparison of fatigue strength of $\mathrm{C} 2$ pedicle screws, $\mathrm{C} 2$ pars screws, and a hybrid construct in C1-C2 fixation. Spine (Phila Pa 1976) 39:E12-E19, 2014

35. Tao X, Tian W, Liu B, Li Q, Zhang G: Accuracy and complications of posterior $\mathrm{C} 2$ screw fixation using intraoperative three-dimensional fluoroscopy-based navigation. Chin Med J (Engl) 127:2654-2658, 2014

36. Yu X, Li L, Wang P, Yin Y, Bu B, Zhou D: Intraoperative computed tomography with an integrated navigation system in stabilization surgery for complex craniovertebral junction malformation. J Spinal Disord Tech 27:245-252, 2014
37. Zausinger S, Scheder B, Uhl E, Heigl T, Morhard D, Tonn JC: Intraoperative computed tomography with integrated navigation system in spinal stabilizations. Spine (Phila Pa 1976) 34:2919-2926, 2009

\section{Author Contributions}

Conception and design: Fulkerson, Kovanda. Acquisition of data: Fulkerson. Analysis and interpretation of data: Fulkerson. Drafting the article: all authors. Critically revising the article: Fulkerson, Kovanda. Reviewed submitted version of manuscript: Fulkerson, Kovanda. Approved the final version of the manuscript on behalf of all authors: Fulkerson. Administrative/technical/material support: Fulkerson. Study supervision: Fulkerson.

\section{Correspondence}

Daniel H. Fulkerson, Indiana University School of Medicine/ Goodman Campbell Brain and Spine, Riley Hospital for Children, 702 Barnhill Dr. \#1134, Indianapolis, IN 46202-5200. email: dfulkers@iupui.edu. 